\title{
Factors related to the achievement of the National License Examination Part 1 of medical students in Faculty of Medicine Vajira Hospital, Navamindradhiraj University
}

\author{
Siriwan Tangjitgamol', Sujitra Tanvanich ${ }^{2}$, Angkana Pongpatiroj ${ }^{3}$, Chiroj Soorapanth $^{4}$
}

\begin{abstract}
Introduction: National License Examination (NLE) is organized by the Consortium of Thai Medical Schools to assess the competency of medical students. Part I-NLE involves an evaluation of basic science knowledge. Our objective was to evaluate factors associated with the results of part-I NLE.

Methods: Learning attitude and behavior, preparation for and attitude towards the NLE were surveyed by a questionnaire given to all third to fifth year students (in 2010) at the institution. Additional data collected were: gender, admission and aptitude tests scores, cumulative grade point average (GPA) during the first two years, and the results of part-I NLE. Association of these factors and the results of the examination were studied.
\end{abstract}

Results: Mean age of 206 participants was $21.1 \pm 0.74$ years. $55 \%$ were female $45 \%$ male. Mean aptitude and admission scores were $18.9 \pm 2.64$ and $51.4 \pm 8.75$, respectively while mean of GPA was $3.0 \pm 0.33$. From the questionnaire: mean scores of learning behavior, preparation and attitude towards the NLE were $3.3 \pm 0.40,3.1 \pm 0.57$, and $3.3 \pm 0.61$, respectively. There were $174 / 206$ students who passed the NLE. Factors significantly associated with achievement were: good GPA $\geq$ 3.0 , good learning behaviors (score $\geq 3.0$ ), and good preparation for the examination (score $\geq 3.2$ ).

Conclusions: Recent academic effort and performance (represented as GPA and behaviors in learning and preparation for the examination) were more important than remote academic background (represented as aptitude and admission scores).Medical teachers should stimulate students to have continuous effort in learning and preparation for the examination.

Keywords: national license examination, learning attitude, learning behavior, preparation methods for the examination, attitude towards the NLE

\section{Introduction}

Medicine is a profession which requires an intensive effort from an individual. This starts from a highly competitive admission test continuing to hard work during the course and maintenance of competency after graduation.

\footnotetext{
${ }^{1} \mathrm{MD}$, Department of Obstetrics and Gynecology

${ }^{2}$ M.Sc, Department of Anatomical Pathology

${ }^{3} \mathrm{MD}$, Medical Education and Student Affairs Section; ${ }^{4}$ Department of Orthopedics-

Faculty of Medicine Vajira Hospital, Navamindradhiraj University, Bangkok, Thailand

Corresponding author:

SiriwanTangjitgamol, MD

681 Samsen Road, Dusit District,

Bangkok, 10300 Thailand

Email: siriwanonco@yahoo.com
}

Admission tests to medical school are generally considered as one of the most difficult tests among high school students because there are limited resources outnumbered by a large number of applicants. In Thailand, there are 2 main systems to recruit high school students into a medical school. One is organized by the Consortium of Thai Medical Schools while the other is selforganized by an individual institution. The admission examination by the Consortium is composed of 2 major parts: the general knowledge test $(70 \%)$ and the aptitude test $(30 \%)$. The aptitude test is further subdivided into 4 sections to measure the intelligent quotience, the ability to evaluate linkage, situation analysis, and ethical attitude.

A conventional Thai curriculum for the medical degree is 6 years to. The first three years focuses on preclinical or basic science 
knowledge. The fourth and fifth year is devoted to clinical knowledge, and the sixth year of externship emphasizes clinical skills. Internal examinations are held by each medical school at the end of each semester during the preclinical course and after clinical rotations from each department. The Thai Medical Council has ruled that any graduated doctors from medical schools (either in the country or from abroad) must pass the national board examination for licensure before practicing clinical medicine in Thailand. The examination set by the Thai Medical Council, so called National License Examination (NLE), is comprised of 3 main parts: basic science knowledge taken at the end of third year, clinical science knowledge taken at the end of fifth year, and both knowledge and clinical skills evaluation during the sixth year. This is to standardize the basic competencies of graduate physicians and to assure health consumers will have a standard health care service. Furthermore, this examination serves as reinforcement for medical students to exert their maximal learning efforts during their course.

Many cognitive and non-cognitive factors can influence successful medical education aside from an educating system of an institution and teaching performance of medical personnel (DeAngelis, 2003; Hamdy et al., 2006; James \& Chilvers, 2001; Lumb \& Vail, 2004; McManus et al., 2003). Factors which contribute to successful academic outcomes (including examination results) are for examples: certain personal characteristics, attitude of an individual towards medicine, pre-medical school performance, learning attitudes, learning behavior, stress coping, and conscientiousness (Dyrbye et al., 2005; James \& Chilvers, 2001; Lynch et al, 2009; McManus et al., 2003).

Since there are many factors which may impact effective learning, we aimed to evaluate some potential influencing factors of personal and academic background, learning behavior, preparation and attitude towards the NLE on the examination outcomes. These data will serve as valuable information for medical educators and medical students to facilitate and to prepare, respectively, for the NLE and other medical examinations

\section{Materials and Methods}

After approval from the institution's Ethics Committee for Research involving human subjects, we built a structured self-answered questionnaire. The questionnaire was in Thai language and was modified from the learning and study strategies inventory questionnaire developed by Weinstein et al., (Weinstein, 1987). The modified questionnaire was discussed among researchers until a consensus was reached. The validity of the questionnaire was tested prior to data collection by three Thai experts specialized in medical education. Each expert independently reviewed each question and subsequently approved all questions and content in the questionnaire. Reliability was tested by trial interviews of 30 medical students with similar characteristic features to the study population. The reliability (particular the sections of learning behavior, examination preparation, and the attitude) was analyzed for Cronbach's Alpha Coefficient using SPSS 11.5 (Chicago, IL). The reliability of the questionnaire was 0.8398 .

The questionnaire was divided into 5 sections composing of quantitative and qualitative questions: personal data, admission and aptitude tests scores, GPA, result and score of part I NLE; learning behavior (10 main questions); preparation methods for the examination (12 questions); attitude towards the NLE (9 questions); and additional written comments or opinions toward medical learning and examination. The scores of admission test, aptitude test, and NLE were to be filled unless the participants could not recall their actual score (s) when the nearest range of score was selected from the check score boxes which were in the range of five. The results of the NLE were reported as "pass" or "fail" and also their actual test scores or score in a range of five. The cumulative grade point average (GPA) from the first two years of medical course was additionally obtained from the record of the medical education unit of the institution. Scores of each question from the sections of learning behavior, preparation methods for the examination, and attitude towards NLE ranged from 1 to 5 . Score of 5 meant "strongly agree", 4 "agree", 3 "neutral", 2 "disagree", and 1 "strongly disagree".

The researchers introduced the research proposal and study goal to all third, fourth and fifth year medical students of Navamindradhiraj University year 2010. Inclusion criteria were students who voluntarily agreed to participate. All participants were requested to sign an informed consent form. The number-coded questionnaire did not require any identification data of the subjects. The researchers distributed the questionnaires to the participants, briefly explained the content, and collected it within 1 
hour. Exclusion criteria were student who could not recall both the exact scores and scores in the range of five, or had not answered the entire questionnaire regarding learning behavior, preparation methods for the examination, and attitude towards NLE.

Data were analyzed using SPSS 11.5 (Chicago, IL). Descriptive statistics were used to analyze demographic data and were summarized as numbers with percentage for categorical data. Continuous data of GPA; scores of aptitude test, admission test, NLE; and score of the answer to each question and total score of each part were presented as mean \pm standard deviation (SD) or median with an appropriate range. The scores from negative questions of learning behavior or attitude towards the NLE were reversed to obtain mean/ median score for each question and total mean/ median score of each part. High total mean/ median score indicated good behavior or attitude while low score meant poor behavior or attitude. GPA and scores of aptitude test, admission test, learning behavior, preparation for the NLE, and attitude toward the NLE were then categorized into two groups by their mean/median scores as "higher score or good behavior or attitude" or "lower score or poor behavior or attitude". Mean/median score of references would be rounded to the nearest score of range before categorization if there were students who could remember the examination scores in the range of five but not their exact scores. These factors as well as gender were studied for the association with the result of the NLE by Pearson Chi-square or Fisher exact test as appropriate. Multiple logistic regression analysis identified independent factors for the results of the examination was performed. The outcomes were considered significant only if $p$ value $<0.05$.

Table 1: Demographic characteristic features of the subjects $(N=206)$

\begin{tabular}{lcc}
\hline Demographic data & $\mathbf{n}$ & $\%$ \\
\hline Gender & 114 & 55.3 \\
Female & 92 & 44.7 \\
Male & & \\
Grade point average (GPA), mean \pm SD = 3.0 $\pm \mathbf{0 . 3 3}$ & 1 & 0.5 \\
$\quad<2.00$ & 7 & 3.4 \\
$2.00-2.49$ & 81 & 39.3 \\
$2.50-2.99$ & 117 & 56.8 \\
$\geq 3.00$ & & \\
Admission score, mean \pm SD $=\mathbf{5 1 . 4} \pm \mathbf{8 . 7 5 *}$ & 17 & 8.3 \\
$35-39.99 \%$ & 52 & 25.2 \\
$40-44.99 \%$ & 22 & 10.7 \\
$35-39.99 \%$ & 18 & 8.7 \\
$50-54.99 \%$ & 58 & 28.2 \\
$45-49.99 \%$ & 32 & 15.5 \\
$60-64.99 \%$ & 7 & 3.4 \\
$65-70.0 \%$ & & \\
Aptitude test score, mean $\mathbf{1 8 . 9} \pm \mathbf{2 . 6 4}$ & 10 & 4.9 \\
$<15 \%$ & 102 & 49.5 \\
$15-19 \%$ & 94 & 45.6 \\
$20-24 \%$ & - & - \\
$25-30 \%$ & & \\
\hline
\end{tabular}

*Mean admission score was obtained from 128 students who could recall their exact scores 


\section{Results}

Out of 239 students from the three academic years, 23 students declined to participate in the study. Among 216 who consented to participate, 10 did not respond to all questions of learning behavior, preparation methods for the examination, and attitude towards NLE were excluded. A total of 206 students were included in the study. Their mean age was $21.1 \pm 0.74$ years old. More than half were females (114 subjects or 55.3\%). Mean aptitude score of all 206 students was $18.9 \pm$ 2.64 while mean admission score of $12 \overline{8}$ students who could recall their accurate score was $51.4 \pm 8.75$. The performance of the students during the first two years was relatively good with a mean GPA of $3.0 \pm 0.33$. Table 1 shows gender and proportion of students according to ranges of aptitude and admission tests as well as their GPA.

Regarding learning behavior of students, the total mean score of all questions was $3.3 \pm$
0.40 . Each mean score of most parameters was in the range of 3.0-3.8 with an exception of the self-preparation pre- and post-class selfpreparation which scored only 2.6 (Table 2). For behavior of preparation for the national license examination, the total mean score of the examination preparation was $3.1 \pm 0.57$. Variation was observed among the 12 items of measurement the scores ranging from 2.14.1. Higher mean scores of 3.8-4.1 were related to attendance to teacher-run tutorial sessions, review of old test questions, and more student efforts prior to examination. Low scores of 2.1-2.7 were related to lack of regular study or long term preparation for the examination (Table 3). As regards to the attitude of the students towards the NLE, all positive attitudes (items 1-5) had the mean scores of 3.0 to 4.1 while the mean scores from the five negative attitudes varied from 2.3 to 3.7. Table 4 shows primary and reverse mean attitude scores. Mean score of all evaluated items of the attitude was $3.3 \pm 0.61$.

Table 2: Learning behavior of the subjects $(N=206)$

\begin{tabular}{lc}
\hline Behavioral aspects ( mean total score $=\mathbf{3 . 3} \mathbf{0 . 4 0}$ ) & Mean score $\mathbf{\text { SD }}$ \\
\hline Attitude toward learning in the classrooms* & $3.8 \pm 0.55^{*}$ \\
Motivation & $3.5 \pm 0.65$ \\
Study schedule arrangement & $3.2 \pm 0.67$ \\
Anxiety* & $3.3 \pm 0.58^{*}$ \\
Concentration on class activity* & $3.5 \pm 0.60^{*}$ \\
Learning strategies and correlation of knowledge & $3.5 \pm 0.69$ \\
Identification and selective memorization of the core issues & $3.0 \pm 0.67$ \\
Applying various strategies and techniques in learning & $3.1 \pm 0.74$ \\
Self pre- and post-class preparation & $2.6 \pm 0.73$ \\
Techniques for examination preparation* & $3.0 \pm 0.64^{*}$ \\
\hline
\end{tabular}

${ }^{*}$ Reversed mean score in each negative question was used to obtain mean total score 
Table 3: Preparation for the National license examination $(N=203)$

\begin{tabular}{|c|c|c|}
\hline \multicolumn{2}{|r|}{ Preparation for the examination (mean total score $=3.1 \pm 0.57$ ) } & \multirow{2}{*}{ Mean score \pm SD } \\
\hline I & practiced the following activities to prepare for the examination. $I \ldots$. & \\
\hline 1. & $\ldots$ was or have been the leader of the tutorial group & $2.6 \pm 1.07$ \\
\hline 2. & $\ldots$ attended the peer-tutorial session & $2.8 \pm 1.12$ \\
\hline 3. & $\ldots$ attended the teacher-tutorial session & $3.8 \pm 1.03$ \\
\hline 4. & ... mainly reviewed old test papers of national license examination & $3.8 \pm 0.97$ \\
\hline 5. & $\ldots$ reviewed old test papers along with the lessons & $4.1 \pm 0.96$ \\
\hline 6. & ... prepared for the examination during semester break & $2.1 \pm 1.20$ \\
\hline 7. & ... prepared for the examination during the whole third year of medical course & $2.4 \pm 1.16$ \\
\hline 8. & ... studied hard especially prior to the national license examination & $4.0 \pm 0.97$ \\
\hline & ... regularly attended the class prior to the examination & $3.9 \pm 1.00$ \\
\hline & ... regularly studied the English text book & $2.9 \pm 0.10$ \\
\hline & ... regularly studied the text books with a section of exercised questions and answers & $2.5 \pm 0.97$ \\
\hline 12. & ... used a mind-mapping technique in preparation for the exam & $2.3 \pm 1.04$ \\
\hline
\end{tabular}

Table 4: Attitude towards the National license examination $(N=203)$

\begin{tabular}{|c|c|}
\hline Attitude towards the national license examination (mean total score $=3.3 \pm 0.61$ ) & Mean score \pm SD \\
\hline \multicolumn{2}{|l|}{ I think that the national license examination .... } \\
\hline 1. ... is mandatory to maintain the professional standard & $4.1 \pm 0.93$ \\
\hline $\begin{array}{l}\text { 2. ... is to reassure that the students have adequate knowledge to continue with } \\
\text { clinical learning }\end{array}$ & $3.5 \pm 1.03$ \\
\hline 3. ... gives me a definite objective during pre-clinical learning & $3.1 \pm 1.11$ \\
\hline 4. ... stimulate my enthusiasm during pre-clinical learning & $3.0 \pm 1.11$ \\
\hline $\begin{array}{l}\text { 5. ... makes me review the content in pre-clinical content before proceeding to } \\
\text { clinical learning }\end{array}$ & $4.1 \pm 0.88$ \\
\hline \multirow[t]{2}{*}{ 6. .... causes selfishness among class members* } & $2.8 \pm 1.23$ \\
\hline & $\left(3.3 \pm 1.23^{* *}\right)$ \\
\hline \multirow[t]{2}{*}{ 7. ... is a waste of time if the particular content will not be used in clinical practice* } & $3.0 \pm 1.14$ \\
\hline & $\left(2.9 \pm 1.14^{* *}\right)$ \\
\hline \multirow[t]{2}{*}{ 8. .... adds stress to the students* } & $3.7 \pm 1.05$ \\
\hline & $\left(2.3 \pm 1.05^{\star *}\right)$ \\
\hline \multirow{2}{*}{$\begin{array}{l}\text { 9. .... should not be held because it causes ranking comparison among institutions } \\
\text { in Thailand* }\end{array}$} & $2.3 \pm 1.12$ \\
\hline & $\left(3.7 \pm 1.12^{* *}\right)$ \\
\hline
\end{tabular}

* The negative questions were presented as such

${ }^{* *}$ Reversed mean score in each negative question was used to obtain total mean score 
Overall 178 out of 206 students (86.4\%) passed the part I - NLE. Although all accomplished students could recall the scores ranges they achieved, only 118 students could remember their exact scores with a mean score of $61.1 \pm 6.30$. The number of students according to the results of the NLE and their scores ranges are shown in Table 5.

Table 5: The results of National License Examination $(N=206)$

\begin{tabular}{lcc}
\hline Result of National license examination & $\mathbf{N}$ & $\%$ \\
\hline Result of the national license examination & & \\
$\quad$ Pass & 178 & 86.4 \\
$\quad$ Fail & 28 & 13.6 \\
Ranges of National license scores & 30 & \\
$\quad<54 \%$ & 62 & 14.6 \\
$54 \%-55.99 \%$ & 64 & 30.1 \\
$60 \%-64.99 \%$ & 39 & 31.1 \\
$65 \%-69.99 \%$ & 9 & 18.9 \\
$70 \%-74.99 \%$ & 1 & 4.4 \\
$75 \%-79.99 \%$ & 1 & 0.5 \\
$80 \%-85 \%$ & & 0.5 \\
Level of National license scores (n=178) & 114 & \\
Higher score (score $\geq 60)$ & 64 & 64.0 \\
Lower score (score < 60$)$ & & 36.0 \\
\hline
\end{tabular}

Gender, academic background (GPA, aptitude score, admission score), learning behavior, preparation and attitude towards the examination of the students were categorized into groups of male vs female or higher vs lower scores by using their means as points of reference. For the admission score, we rounded down the mean scores of 51.4 (from 128 students who could remember their exact scores) and used the score of 50 as the point of reference to determine groups of higher or lower scores. The association of these factors to examination results was studied. From 206 students, we found that higher GPA $\geq 3.0$ and higher behavioral scores in learning and preparation for the examination were significantly associated with passing the examination $(p<$ 0.001 and $p=0.001$, respectively) (Table 6). By multiple logistic regression analysis after adjusted for other factors, we found that higher GPA and higher scores in preparation for NLE were significant factors for passing the NLE with relative risk of $0.06(p<0.001)$ and 0.277 $(p=0.039)$, respectively.

\section{Discussion}

Since the Medical Council has required that all graduated doctors must pass the national board examination for licensure before practicing clinical medicine, all involved parties are cautious to improve their medical education to achieve the goal. Any potential factors which can predict the examination achievement or failure of our medical students will certainly be useful.

Many characteristic of students were included as possible factors influencing the result of the NLE. These seven factors were: personal factor (gender), academic background (GPA, aptitude, and admission scores), and intrinsic factors (learning and examination behavior as well as attitude toward the NLE). Although high school grade was reported by some as a useful predictor of medical study (Abdulrazzaq \& Ibrahim, 1993; Al-Nasir \& Robertson, 2001; Haidinger et al., 2006; Lumb \& Vail, 2004) especially premedical school grade in science

Table 6: Association between personal background and the result of national license examination 


\begin{tabular}{|c|c|c|c|}
\hline \multirow[t]{2}{*}{ General data (N) } & \multicolumn{2}{|c|}{$\begin{array}{l}\text { Result of NLE } \\
\qquad(\mathrm{N}=206)\end{array}$} & \multirow[t]{2}{*}{$P$ value } \\
\hline & $\begin{array}{l}\text { Passed } \\
(n=178)\end{array}$ & $\begin{array}{l}\text { Failed } \\
(n=28)\end{array}$ & \\
\hline \multicolumn{4}{|l|}{ Gender } \\
\hline Female & $103(90.4)$ & $11(9.6)$ & 0.101 \\
\hline Male & $75(81.5)$ & $17(18.5)$ & \\
\hline \multicolumn{4}{|l|}{ GPA } \\
\hline Higher grade (grade> 3.0 ) & $98(98.0)$ & $2(2.0)$ & $<0.001$ \\
\hline Lower grade $($ grade $<3.0$ ) & $80(75.5)$ & $26(24.5)$ & \\
\hline \multicolumn{4}{|l|}{ Aptitude test } \\
\hline Higher score (score> 19) & $94(85.5)$ & $16(14.5)$ & 0.669 \\
\hline Lower score (score <19) & $84(87.5)$ & $12(12.5)$ & \\
\hline \multicolumn{4}{|l|}{ Admission test } \\
\hline Higher score (score>50) & $102(88.7)$ & $13(11.3)$ & 0.281 \\
\hline Lower score $($ score <50) & $76(83.5)$ & $15(16.5)$ & \\
\hline \multicolumn{4}{|l|}{ Learning behavior } \\
\hline Good behavior (score>3.0) & $83(95.4)$ & $4(4.6)$ & 0.001 \\
\hline Poor behavior (score<3.0) & $95(79.8)$ & $24(20.2)$ & \\
\hline \multicolumn{4}{|c|}{ Preparation for examination behavior* } \\
\hline Good behavior (score>3.2) & $93(94.9)$ & $5(5.1)$ & 0.001 \\
\hline Poor behavior (score<3.2) & $82(78.1)$ & $23(21.9)$ & \\
\hline \multicolumn{4}{|l|}{ Attitude toward NLE* } \\
\hline Good attitude (score $>3.3$ ) & $97(89.0)$ & $12(11.0)$ & 0.215 \\
\hline Poor attitude (score $<3.3$ ) & $78(83.0)$ & $16(17.0)$ & \\
\hline
\end{tabular}

* Numbers of students who responded to the 2 sections of preparation for examination and attitude towards the examination were 203 for the result of passed vs failed and was 175 for the result of level of scores among passing students

(Al-Nasir \& Robertson, 2001; James \& Chilvers, 2001), Shaban \& Mc Lean, (2011) could not demonstrate that high school grade was important We did not include high school grade as a potential factor in our study because they were not standardized throughout the country but rather depended on the liberality and policy of each school.

Among studied factors, only GPA and behaviors in learning and preparation for the NLE were significant factors. On the contrary, prior academic performance as reflected by aptitude and admission scores appeared to have no influence. This may be interpreted as: 1) the objectives and contents of the admission examination were not congruent with the ones of the NLE; 2) a remote academic background or performance of the student was not as important as a good and continuous learning effort and preparation for the examination. Previous studies found conflicting results regarding the impact of the aptitude or admission test upon entering into a medical school (Julian, 2005; Lynch et al., 2009; Niraula \& Khanal, 2006). Some authors reported that the test did not predict the performance of medical students in their early years (Lynch et al., 2009; Niraula \& Khanal, 2006) while others found that their admission test was useful to determine the medical school performance (Julian, 2005). A direct association of GPA of the first two years prior to part I -NLE demonstrated in our study was also reported by others (Kozar et al., 2007; Shaban \& Mc Lean, 2011). The authors in one of these studies proposed that higher English and/ or cognitive abilities were possible reasons (Shaban \& Mc Lean, 2011). Our country does not assess English proficiency as 
an isolated test but as part of the admission test. Nevertheless, we assumed that competent students generally had good learning behavior during, good preparation for the internal examination resulting in a good GPA. Hence, these three factors altogether contributed to the ultimate success of the NLE.

To provide an effective intervention or remedy, any means to improve these three significant factors would be beneficial to the students with suboptimal performance. To obtain a good GPA, the students should be orientated from the beginning of their medical course to pay attention to every subjects they took during the first two years. These will serve as basic foundation for their learning behavior as well as the examination preparation and future medical practice.

Regarding learning behavior, half of the behavioral aspects scored low (lower than the mean of 3.3). The three learning behaviors which scored lowest among all were: identification and selective memorization of the core issues, self pre- and post-class preparation, and techniques for examination preparation. Improvement may be achieved in several ways. For example, identification and selective memorization of the core issues may be carried out by students themselves by doing notes taking. This will help students to develop the analytical thinking process and problems solving which is the characteristic of most NLE questions. Mind mapping was also very useful with many potential applications to clinical education. Aside from the instructor who can use it as a teaching resource (Edwards, 2010), students can prepare a mind map by themselves to emphasize important issues from the topics (D'Antoni et al., 2010). Mind mapping help medical students organize, integrate, and retain information by facilitating information retrieval and critical thinking in medical students especially those with the motivation to do it (D'Antoni et al., 2010; Farrand et al., 2002). The self pre- and postclass preparation may get better if they are reenforced by the pre-test and post-test or regular quizzes. There were reports which demonstrated a direct relationship between frequency of the quiz and learning or knowledge retention of the student (Karpicke \& Roediger, 2007; Roediger \& Karpicke, 2006) and significantly correlated with improved academic achievement (Poljicanin, 2009). The quiz yields several advantages to the students: reinforcing or encouraging consistent effort, improving confidence, decreasing stress during a major or final examination, and reducing the time needed for examination preparation (McLean, 2001).

For examination preparation, more than half of the behavioral aspects scored low (lower than mean of 3.1). The three aspects with lowest score were: preparation remote from the examination either during semester break or the whole year prior to the examination, and using a mind-mapping technique in preparation. These problems indicated that long term or continuous learning or preparation and a use of mind mapping or summarization of the subjects' core content are crucial for accomplishments. Students should understand an emerging concept of student-centered learning, and they should take full responsibility for their learning while the teacher will only act as a facilitator and resource person (McLean \& Gibbs, 2010).

Few limitations were encountered in our study. First, most of the information was obtained from the students themselves the numerical data from the participants may be inaccurate especially when the questionnaire was done remote from the examination. Verification of data was not possible because virtual data were authorized and could be accessed by only the students. Nevertheless, the ranges of scores were provided to obtain a close value. With narrow ranges of standard deviation obtained, we interpret these figures are fairly reliable. Second, the project offered no incentive compensation for the participants. Hence, the participants might be less concentrated to respond to each question in the questionnaire.

The outcomes of our study reflected the problems student had during their course. The medical educators should consider these issues in order to improve medical education of the institution. Medical students should be monitored early and continuously in their course to identify the students who are at risk of failure, so appropriate support can be provided in a timely manner at different stages of their course (Holmes, 2002; James, 2008; McLean \& Gibbs, 2009; McLean \& Gibbs, 2010; Van Wyk et al., 2007). Further studies should be conducted to cover all stages of their education to identify other possible causes of success and failure. We also believe that the study on this subject should also be conducted of the national level to evaluate and to improve the overall quality of teaching and learning of medicine in Thailand.

Acknowledgement 
We thank Assoc. Prof. Panadda Rojpibulstit for her contribution in forming and validating the questionnaire and Ms. Supaporn Palsree, Ms. Apiradee Samsri, Mr. Jutturong Ckumdee for their administrative contribution.

\section{Contributors}

All authors contributed to initial discussion and conception for the manuscript. ST and ST: outlined the topics; performed literature review; collected data; wrote the initial draft; reviewed and revised the subsequent drafts; compiled and approved the final manuscript. AP: wrote portions of the initial draft; and reviewed the revisions. JS: constructed and validated the questionnaire; reviewed and approved the final manuscript.

\section{References}

Abdulrazzaq, Y. \& Ibrahim, K. (1993) Could final year school grades suffice as a predictor for future performance? Medical Teacher, 15 (2-3), pp. 243-251.

Al-Nasir, F. \& Robertson, A. (2001) Can selection assessments predict students' achievements in the premedical year? A study at Arabian Gulf University.Education for Health (Abingdon, England), 14 (2), pp. 277-286.

D'Antoni. A.V., Zipp, G.P., Olson, V.G. \& Cahill, T.F. (2010) Does the mind map learning strategy facilitate information retrieval and critical thinking in medical students? $B M C$ Medical Education, 10, p.61. PMID: 20846442

DeAngelis, S. (2003) Non-cognitive predictors of academic performance.Going beyond the traditional measures. Journal of Allied Health, 32 (1), pp. 52-57.

Dyrbye, L.N., Thomas, M.R. \& Shanafelt, T.D. (2005) Medical student distress, Causes, consequences, and proposed solutions. Mayo Clinic proceedings, 80 (12), pp.1613-1622.

Edwards, S. \& Cooper, N. (2010) Mind mapping as a teaching resource. The clinical teacher, 7 (4), pp. 236-239.

Farrand, P., Hussain, F. \& Hennessy, E. (2002) The efficacy of the 'mind map' study technique. Medical Education, 36 (5), pp. 426-431.

Haidinger, G., Frischenschlager, O. \& Mitterauer, L. (2005) Prediction of success in the first-year exam in the study of medicine - a prospective survey. Wiener klinischeWochenschrift, 117 (23-24), pp.827-832. (Abstract).

Haidinger, G., Frischenschlager, O. \& Mitterauer, L. (2006) Reliability of predictors of study success in medicine. Wiener klinische Wochenschrift, 156 (13-14), pp.416-420. (Abstract).

Hamdy, H., Prasad, K., Anderson, M.B., Scherpbier, A.,Williams, R.\& Zwierstra, R, et al., (2006)
BEME systematic review, Predictive values of measurements obtained in medical schools and future performance in medical practice. Medical Teacher, 28 (2), pp. 103-116.

Holmes, D. (2002) Eight years' experience of widening access to medical education.Medical Education, 36 (10), pp.979-984.

James, D. \& Chilvers, C. (2001) Academic and nonacademic predictors of success on the Nottingham undergraduate medical course 1970-1995. Medical Education, 35 (11), pp. 1056-1064.

James, D., Ferguson, E., Powis, D., Symonds, I.\& Yates, J. (2008) Graduate entry to medicine: Widening academic access and socioeconomic access. Medical education, 42 (3), pp.294-300.

Julian, ER. (2005) Validity of the medical college admission test for predicting medical school performance. Academic medicine, 80 (10), pp. 910-917.

Karpicke, J.D. \& Roediger, H.L. 3rd ed (2007) Expanding retrieval practice promotes shortterm retention, but equally spaced retrieval enhances long-term retention. Journal of experimental psychology Learning, memory, and cognition, 33 (4), pp.704-719.

Kozar, R.A., Kao, L.S., Miller, C.C. \& Schenarts, K.D. (2007) Preclinical predictors of surgery NBME exam performance.Journal of Surgical Research,140 (2), pp.204-207.

Lumb, A.B. \& Vail, A. (2004) Comparison of academic, application form and social factors in predicting early performance on the medical course. Medical education, 38 (9), pp.10021005.

Lynch, B., MacKenzie, R., Dowell, J., Cleland, J.\& Prescott, G. (2009) Does the UKCAT predict year 1 performance in medical school.Medical education, 43 (12), pp. 1203-1209.

McLean, M. (2001) Introducing a reward system in assessment in histology, a comment on the learning strategies it might engender. $B M C$ Medical Education, 1 (7), PMID: 11741511

McLean, M \& Gibbs, T.J. (2009) Learner-centred medical education: Improved learning or increased stress? Education for Health (Abingdon, England), 22 (3), p. 287.

McLean, M. \& Gibbs, T. (2010) Twelve tips to designing and implementing a learner-centred curriculum, Prevention is better than cure. Medical Teacher, 32 (3), p.225-230.

McManus, I.C., Smithers, E., Partridge, P., Keeling, A. \& Fleming, P.R. (2003) A levels and intelligence as predictors of medical careers in UK doctors, A 20 year prospective study. British Medical Journal, 327 (7407), pp.139-142.

Niraula, S.R. \& Khanal, S.S. (2006) Critical analysis of performance of medical students. Education 
for Health (Abingdon, England), 19 (1), pp.513.

Poljicanin, A., Carić, A., Vilović, K., Kosta, V., MarinovićGuić M. \& Aljinović, J., et al., (2009) Daily mini quizzes as means for improving student performance in anatomy course. Croatia Medical Journal, 50 (1), pp. 55-60.

Roediger, H.L. III. \& Karpicke, J.D. (2006) Testenhanced learning, taking memory tests improves long-term retention.Psychological Science, 17 (3), p. 249-255.
Shaban, S. \& Mc Lean, M. (2011) Predicting performance at medical school, can we identify at-risk students? Advances in Medical Education and Practice, 2, p. 139-148. DOI: 10.2147/AMEP. S19391

Weinstein, C.E., Palmer, D.R. \& Schulte, A.C. (1987) Learning and Study Strategies Inventory. Clearwater, FL: H \& H Publishing. 